\title{
Why is there No Nobel Prize in Mathematics?
}

\author{
by Lizhen Ji \\ Department of Mathematics, University of Michigan
}

\section{Introduction ${ }^{1}$}

The question of why there is no Nobel prize in mathematics has been asked by many people many times and will continue to be asked by new generations of mathematicians. The title Why is there no Nobel prize in mathematics has also been used by several published articles. One article was written by two leading mathematicians (or analysts, in view of the alleged connection with the Swedish analyst Mittag-Leffler), Lars Garding and Lars Hörmander: Is There No Nobel Prize in Mathematics? Mathematical Intelligencer 7:3 (1985), 73-4. Another article was written by the mathematician Peter Ross: Why Isn't There a Nobel Prize in Mathematics? Math Horizons, November 1995, pg. 9. This question was also raised in a paper written by a famous Swiss mathematician, Beno Eckmann, for the ICM 1994 in Zurich: Mathematics: Questions and Answers. Amer. Math. Monthly 102 (1995), no. 8, 685-690. There is also a lot of discussion about this question on the website http://almaz.com/nobel/ why_no_math.html

Garding and Hörmander did not approve the popular reason: "Mittag-Leffler had had an affair with Nobel's wife," ${ }^{2}$ and gave their definite explanations: "Nobel was a confirmed bachelor." So the matter should have been settled.

Or it seemed so to me until I had a chance to visit the Nobel Museum in Stockholm in early 2012. I will describe below what I learned during the visit to the museum and from the later reading of biographies of Nobel. The conclusion is that Nobel had the most interesting and dramatic life, and women played a huge role in his life and in the evolvement of the Nobel prize. The combination of many special things made the Nobel prize possible.

Though mathematics has played no role in the life of Nobel at all, there is a good reason for the above most

\footnotetext{
${ }^{1}$ This article represents the personal opinions of the author. It does not necessarily reflect the views of the editorial board of this journal. - Eds.

${ }^{2}$ The reason for the popularity of this reason is clear. By a Chinese saying, "Heroes cannot pass the gate of beauty." As a corollary, non-heroes cannot stopping about heroes and the gate of beauty (i.e., people often like to hear juicy stories).
}

popular reason for no Nobel Prize in mathematics. One of the purposes of this article is to answer this question. As we will see below, it might be a good joke on mathematicians by non-mathematicians or by some proud mathematicians.

After reading this article, the reader may decide that maybe a better alternative title should be Nobel, women and mathematics. But this might be a bit too sensational and not serious enough for an article related to mathematics.

Before we discuss more about Nobel, we should probably address the question why we discuss the life of Alfred Nobel, in particular his love life. One reason is that almost everyone in the world knows about the Nobel prize. For many smart people, the life time goal is to get a Nobel prize, and in October of each year, the general public is also curious about who will get a Nobel prize. But the surprising thing is that few people know about the life of Nobel or even care to ask about this person who was behind the most famous prize in the world. Even fewer people know about his complicated life, especially his love life. One purpose of this article is to tell the unusual love life of Nobel. Of course, many famous people have colorful and unusual love lives too. But what is special about the love life of Nobel is that without his romantic relationships mentioned below, there would be no Nobel prizes, and the world of science might be different. (We can all argue about the positive and negative impacts of the Nobel prizes). Therefore, the love life of Nobel explains the origin of the Nobel prizes, and this alone might justify to learn about the love stories of Nobel. Of course, understanding better the above reason for no Nobel prize in mathematics is another motivation, which was my original motivation to start this project.

In some sense, love, and romantic love, is the most important thing in life. Good artists and poets are supposed and expected to have many lovers. One reason is that they may (or are supposed to) have more imagination, and romantic relations inspire them. This brings up an interesting and difficult topic on relations between "Passion" and "Imagination." One could argue whether this is a good, selfish excuse used by geniuses. Maybe we can consider some examples. One of the most famous modern painters is Pablo Picasso. He had many lovers and often 
painted his wife and mistresses in the same picture. When I first saw such a picture in the art museum of our university, I was puzzled and amused. There have been many discussions about this topic. For example, according to a description of a special exhibition of Picasso at the de Young fine arts museum in San Francisco in 2011: "Behind every great artist, there is a muse. For Picasso, his romantic relationships provided inspiration for countless paintings, drawings and sculptures. The exhibition highlights many powerful depictions of Picasso's lovers Marie-Thérèse Walter and Dora Maar, among others, while touching on every major phase of his expansive career."

Okay, artists have good reasons to have many lovers. How about mathematicians or scientists? According to many people, physicists have more imagination than mathematicians and they should have more reasons or excuses for more romantic relations. One good example is the famous physicist, Erwin Schrödinger. His multiple over-romantic relations with young girls are certainly beyond most people's expectation. (If a reader wants to read more about Schrödinger's life, a good biography is

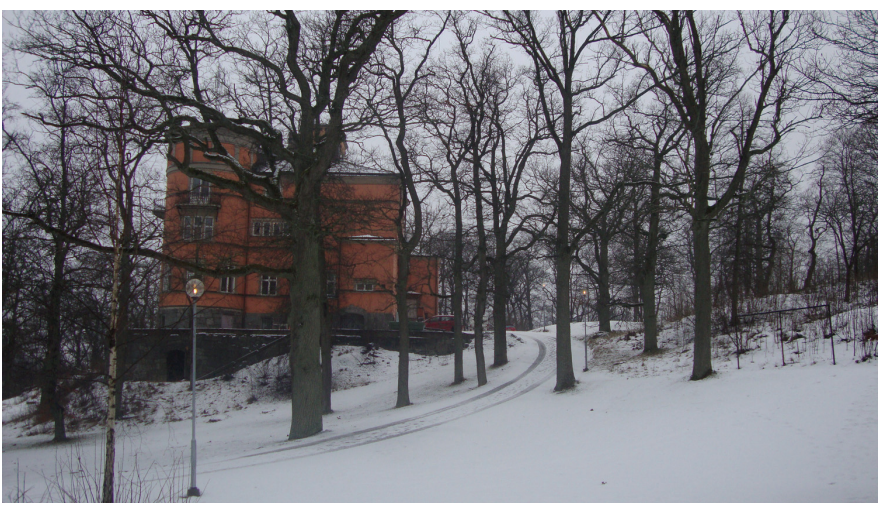

Institut Mittag-Leffler

A Life of Erwin Schrödinger, written by Walter J. Moore, Cambridge University Press; Abridged edition, 1994.)

It is not clear whether there has been any great mathematician who has been as much romantic, or whether romantic relations had inspired some great theories or results in mathematics. Let us look at one example by asking a usual question "who is the most original mathematician in the history." It is probably difficult to answer this since there might be too many candidates. The question "who is the most original mathematician and ahead of his time in the history" might still be difficult to answer. But I am sure that most people will have a definite answer to the more restricted question "who is the most original mathematician, ahead of his time and not recognized in his life time." The answer should be Évariste Galois. It is difficult to imagine modern mathematics without the notion of groups. It is also difficult to judge the impact of romantic relations on the mathematics of Galois, but most people will also probably agree that his tragic death caused by a woman made him, or the discovery of group theory, more interesting.
A reader of this article might be surprised by the relationship of the much older Nobel with his young girlfriend. But this is also normal. It has been going on before and after Nobel, and it will continue forever as long as civilization exists for many obvious reasons. We can all cite a famous romantic story of a famous Chinese physicist. Another less known, at least less talked about, example involves the father of modern China.

In conclusion, the love life of Nobel is not only interesting but also shed light on the Nobel prize and should not be avoided.

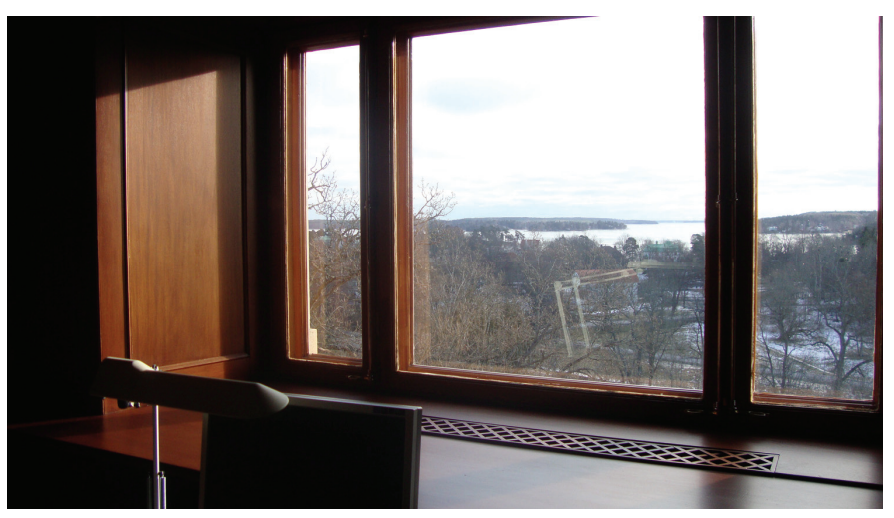

\section{The Nobel Museum}

Near the end of February 2012, I had a chance to visit the famous Institut Mittag-Leffler. There are many stories about Mittag-Leffler. For example, he married a rich wife and his house was turned into the mathematics institute. He started the famous math journal Acta Mathematica. He got a job for the most charming and distinguished female mathematician in history, Sofia Kovalevskaya. There is a good article about Mittag-Leffler and his institute: The Dream of a Swedish Mathematician: The Mittag-Leffler Institute by Allyn Jackson, in Notices of AMS, September 1999. In view of the topic of this article, it may not be too far fetched to quote from page 1051 of this article: "One of Mittag-Leffler's first feats upon going to Stockholm was to arrange a position for the brilliant Sonya Kowalevski, whom he had heard of while in Berlin. Kowalevski had been a private student of Weierstrass and had received a doctorate in Göttingen, but because she was a woman she could not hope for a permanent position in the old universities in Europe. In 1884 Kowalevski moved from St. Petersburg to Stockholm and began the five-year position Mittag-Leffler had arranged for her. Intelligent and charming, Kowalevski was a sensation in the social scene of Stockholm. She attracted many admirers, including the Arctic explorer Fritjof Nansen and the industrialist Alfred Nobel, whose advances she is said to have found quite ridiculous, as he was 17 years her senior." Maybe this did not seem ridiculous to Nobel. As we will see below, his girlfriend was more than 20 years younger than him. 
Institut Mittag-Leffler is in a small village of the richest residential suburb of Stockholm. It is located on a hill with a nice view of the North Sea from the third floor. It takes 15 minutes to walk to the sea shore from Institut Mittag-Leffler. It is common that rivers and lakes are frozen up in the winter, especially in Michigan. But it was impressive for me to see that the north sea was frozen too.

Institut Mittag-Leffler has a good mathematics library and the village is charming and peaceful (since there is nothing else besides the sea and residential houses). It was a good place to do math. In fact, I was working very hard (almost around the clock) on my book on great

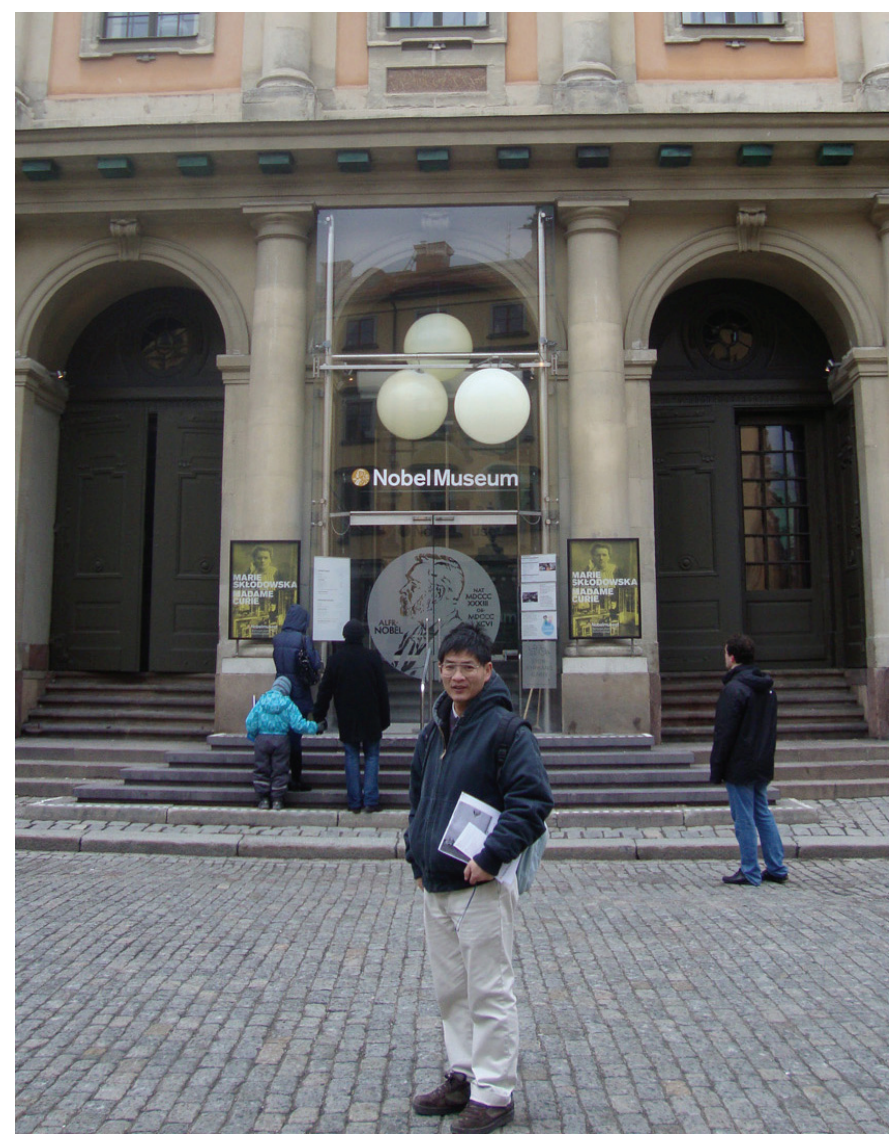

Lizhen Ji

mathematics books. It became boring after a few days. So on one afternoon I decided to visit the downtown of Stockholm, which is the capital and the largest city of Sweden and the most populated urban area in Scandinavia. It is supposed to be beautiful and charming with bays, canals and old buildings. One could imagine that a walk along the waterfront in the summer is really pleasant. I passed by an impressive building and saw a sign reading "Nobel Museum."

I hesitated to visit this museum since I needed to go back to the remote village of Institut Mittag-Leffler via a combination of subway and bus before it becomes dark. I also thought that there were not too much new things I could learn from the museum since I have heard of the Nobel prize and met some Nobel prize winners. Maybe many people thought the same, and few people entered the museum while I was thinking. But the frozen water and the cold weather did not make staying outside too interesting, and I decided to go inside. What I found totally surprised me.

In the main hall, there are signs and pictures displaying some prominent Nobel laureates. There were so

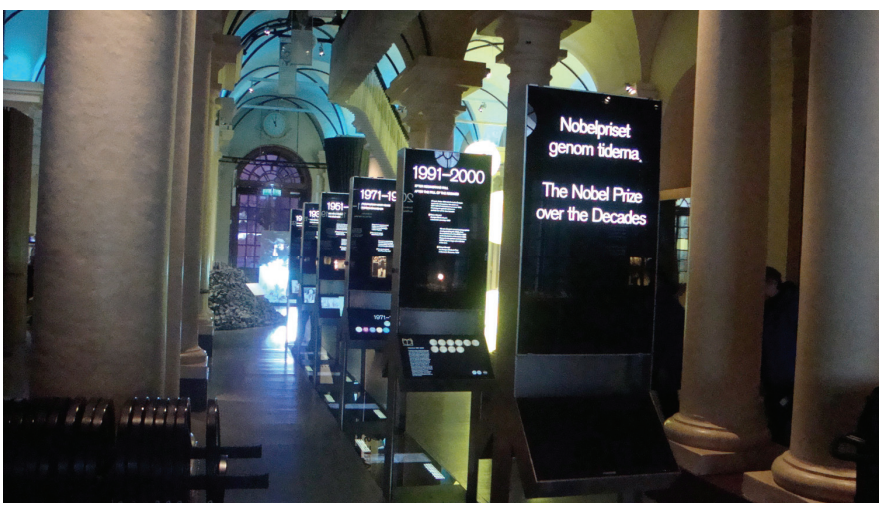

many Nobel laureates and the museum did not have space to display their pictures or descriptions of their works. They hanged up many pictures in stacks close to the ceiling, which are moved around periodically. One would ignore them if one were not careful. I had never heard of most of them. This makes one wonder what is the meaning of being famous.

The museum is a small place. When I turned right, I entered a room devoted to the life of Alfred Nobel. There is a timeline of his life and some description of important

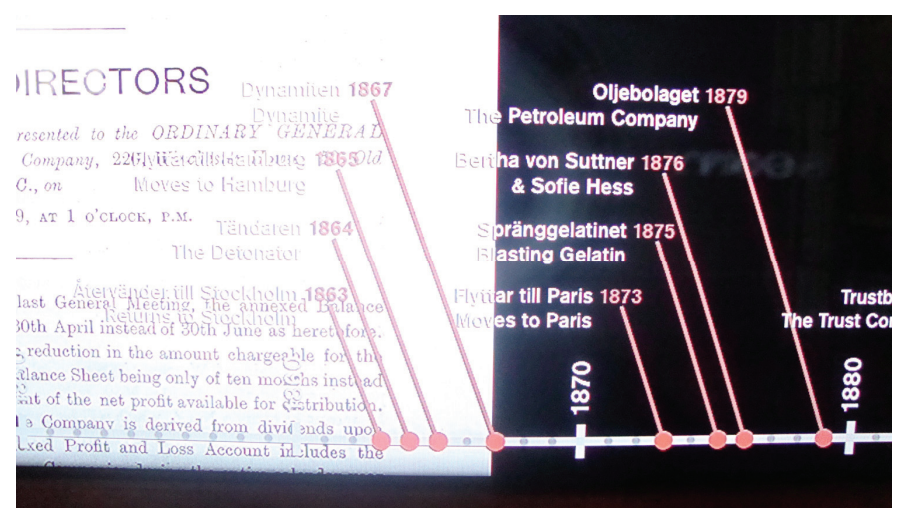

events and people in his life. I saw pictures of two women. One has the appearance of belonging to a royal family and the other is very charming. The word description next to the picture of the charming one surprised me. I quote them directly: "In the spa town of Baden bei Vien, Nobel meets an Austrian woman named Sofie Hess. They begin a troubled relationship, which lasts for eighteen years."

My curiosity was aroused immediately. I did not know that Nobel was in a relationship for such a long time since he was not married. I also wondered what happened to their relationship. 
I moved on. In a display of a summary of his life titled "Citizen of the World," it says:

"By 1870s, his industrial empire has grown large, with companies and factories in places like Germany, Great Britain, France, Italy, Switzerland and Spain... His love life, on the other hand, was rather less successful. In 1876 he began a relationship with a woman by the name of Sofie Hess, which continued for many years, though it became stormy and complicated. In 1890, Sofie Hess became pregnant by another man, whom she eventually married."

This was even more shocking to me. In a museum in honor of Nobel, it seems to be a great disgrace and no respect to him to say prominently that his woman was

\section{On the Road with Pen in Hand}

"How pitiful to strive to be someone or something

in the motley crowd of 1.4 billion two-legged,

tailless apes, running around on our revolving earth

projectile," writes Alfred Nobel in one of his thousands

of letters. But in spite of this expression of futility,

Nobel "ran around" like few others of his species.

Early in life he had learnt to live in a state of

constant preparedness to move. He was born into a family whose financial situation was tenuous and they kept moving here and there. Nobel spent the majority of his childhood in Stockholm and the remainder of his youth in St. Petersburg, Russia. In his late teens he was sent on a two-year study trip through Sweden, Germany, France, Italy and North America. By the time he had turned 20, Nobel was rightly able to call himself cosmopolitan.

made pregnant by another man and their relationship ended. I cannot imagine that such a thing can happen in a museum in China dedicated to the memory of a famous person.

There was no more information about Sofie Hess or her eventual husband. I continued the tour. The other woman was Bertha von Suttner. She was Nobel's secretary for one week but got married to another man after that. They remained in contact throughout their life.

The place was really small and I finished the tour quite rapidly. But several questions remained in my head. After I went back to Institut Mittag-Leffler, I tried to get more information about Nobel and Sofie Hess but could not find more.

I said to myself that some day I will learn more about Nobel and write an article about this aspect of his life. That someday did not come until the end of October when I went to the Ann Arbor District Public Library to borrow biographies of great people for my youngest daughter. I saw the name Alfred Nobel on a book cover and picked it up. I liked it and wanted to read more about Nobel. In fact, I wanted to get all biographies about him. Unfortunately, the largest bookstore Barnes \& Noble does not carry any biography of Nobel. A list of books on Nobel I found is included in the last section with some excerpts. What I found out is simply amazing. The life of Alfred Nobel is more interesting and complicated than most stories in movies and novels. Here is a summary of some high points.

1. He and his father disputed over his first major discovery and patent.

2. His girlfriend Sofie Hess was trained to be a girlfriend of a rich man (i.e., trained to look beautiful and attractive, and to act and talk in appropriate manners). He did not really like her but could not leave or stop communicating with her until she was married.

3. He and his girlfriend Sofie Hess exchanged hundreds of very intimate letters, and Hess saved these letters and used them to blackmail the Nobel foundation for money.

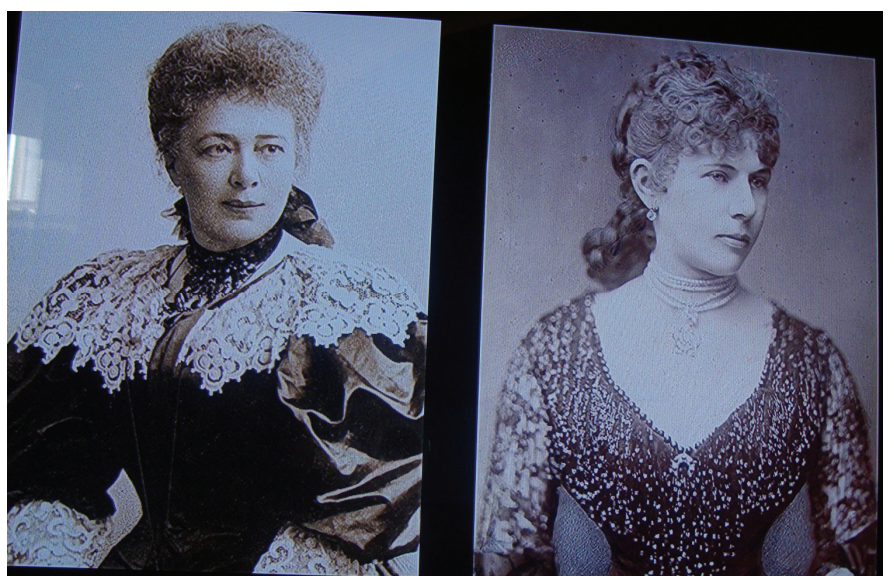

4. He fell in love with his secretary on the second day of her job but failed to win her heart. He set up the Nobel Peace Prize, hoping that she would get it eventually. And she did get it in 1905.

5. A mistake in a French newspaper awoke him up: what legacy did he want to leave behind, and the idea of Nobel prize was born.

6. He died alone away from any family member or friend and he left a huge amount of money scattered across many countries. 
7. His last assistant was faithful and carried out his will with a loaded gun. The combination of all these events is the legacy of the Nobel prize, the most fa-

\section{During his travels, Nobel also kept up regular written}

correspondence with his business acquaintances,

friends and family. Nobel wrote up to 20-30 letters

a day in up to five different languages. In a letter

to Sofie Hess dated 1889 , he tells-of his desire to escape the stress of a businessman's life:

"I should like to use an entire year of complete rest

to recuperate, and concern myself with science only

for the sake of enjoyment, rather than as a business.

I am once again besieged by people sending appeals

for me to come to London, Scotland, Hamburg, Italy

and so on by telegraph. What a life!"

mous prize in the world. It is hard to estimate its impact on the development of sciences and the civilization.

\section{Why did Nobel set up the Nobel prize?}

The obvious reason is that Nobel wanted his fortune to have an impact on the advancement of sciences and stopping wars around the world.

Probably, another more interesting reason was that he was called the Merchant of Death. In April, 1888, a

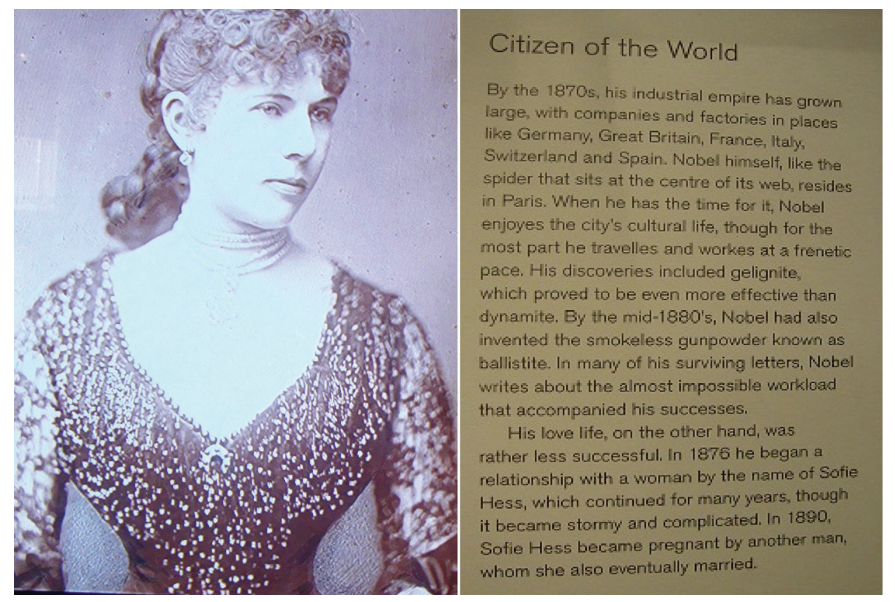

French newspaper published an obituary of the inventor of dynamite. It said that the multimillionaire and world famous recluse, Alfred Nobel, passed away at the age of 57 due to a heart attack. It described him as a "merchant of death," a man whose enormous wealth came mainly from discovering and designing innovative ways to "mutilate and kill" people. The paper also claimed that No- bel's inventions were directly responsible for thousands dying.

The obituary might sound harsh but it told many facts. Most readers probably took a glimpse at it and threw it away. But it really upset one reader in France. It was Alfred Nobel. Nobel was reading his own obituary in his lab in Servan, France, and he did not like it very much.

The newspaper made a mistake. Alfred Nobel's brother, Ludvig Nobel, died of a heart attacked and Alfred Nobel visited his brother at the hospital.

Alfred Nobel was very alive and had eight more years to go. It is true that very few people can read their own obituaries, but he did not feel very lucky. He did not know what he did wrong or what he could do. His inventions could be and had been used for civil purposes, too.

After several days of silence and thinking, he realized that he needed to make changes. He hoped that when his real obituary was going to be published, no phrases like "Merchant of Death" would appear. The idea of the Nobel

\section{Alfred Nobel}

\section{Alfred Nobel passed away on 10 December}

1896 in his home in San Remo. Nathan

Söderblom, future archbishop and Nobel

Laureate, spoke at the commemoration: "His

restless spirit hardly felt the sweet rest for

which others have come here". And if one

was to choose just one word with which to

summarise Alfred Nobel's life, it might well just

be restlessness.

prize started and evolved until he wrote up his final will in December 1895.

In some sense, the French newspaper gave Nobel a golden opportunity. Not many people can see their own death and have a second chance for a new life. Nobel's experience was like the experience of the main character, Scrooge, in the famous novel A Christmas Carol by Charles Dickens. Scrooge was mean and harsh towards the poor people. Before the Christmas Eve, he was visited by three ghosts who showed him his past, his present and his future. He was distressed by what he saw and decided to change his life by helping the less fortunate. After reading this French obituary, Nobel had a clear picture of what others viewed his past and his present. The only thing he could change was his future. 


\section{Nobel's will and testament}

The whole of my remaining realizable estate shall be dealt with in the following way: the capital, invested in safe securities by my executors, shall constitute a fund, the interest on which shall be annually distributed in the form of prizes to those who, during the preceding year, shall have conferred the greatest benefit to mankind. The said interest shall be divided into five equal parts, which shall be apportioned as follows: one part to the person who shall have made the most important discovery or invention within the field of physics; one part to the person who shall have made the most important chemical discovery or improvement; one part to the person who shall have made the most important discovery within the domain of physiology or medicine; one part to the person who shall have produced in the field of literature the most outstanding work in an ideal direction; and one part to the person who shall have done the most or the best work for fraternity between nations, for the abolition or reduction of standing armies and for the holding and promotion of peace congresses. The prizes for physics and chemistry shall be awarded by the Swedish Academy of Sciences; that for physiological or medical work by the Caroline Institute in Stockholm; that for literature by the Academy in Stockholm, and that for champions of peace by a committee of five persons to be elected by the Norwegian Storting. It is my express wish that in awarding the prizes no consideration whatever shall be given to the nationality of the candidates, but that the most worthy shall receive the prize, whether he be a Scandinavian or not.

\section{Which Nobel prize is the most famous?}

There are five categories of Nobel prizes. Each of them is very famous in its own subject. But to the general public, probably the most famous is the peace prize. This is also the most controversial one, and some Nobel peace laureates may not be admired by many people.

The reasons for setting up the prizes in Physics, Chemistry, Physiology or Medicine, Literature are understandable. Nobel was a scientist and used and valued physics and chemistry. Since he was not a healthy person, he naturally wanted and valued progress in medicine.

He always liked literature and has written poems and plays. In his youth, his father was worried that he was too interested in such things instead of carrying on his business in making bombs. Towards the end of his life, he wrote a play, a prose tragedy in four acts about Beatrice Cenci titled "His Nemesis." It was printed while he was dying. The entire stock except for three copies was destroyed immediately after his death, since it was considered as scandalous and blasphemous. The first surviving edition, which is bilingual in Swedish and Esperanto, was published in Sweden in 2003. In 2005 it was translated into Italian. In 2008 it was also translated into French and
Spanish and in 2010 it was published in a bilingual Russian-Esperanto edition. The first production of this play was in a theater in Stockholm in 2005.

The reason for the peace prize is also clear. After being called the "merchant of death," he wanted to promote peace and get a good name for himself. Probably a less known reason for the peace prize was that he wanted a woman he really liked to win it in the future. This was Baroness Bertha Kinsky von Suttner and she won the Nobel peace prize in 1905 for her novel Lay Down Your Arms!

The love story of Bertha Kinsky was complicated and full of twists. The description of it in the book Alfred Nobel, Dynamite King, Architect of Peace seems most interesting. After many disappointment in love, Bertha Kinsky was betrothed to Prince Wittgebstein, who against his high-born family's wishes, had taken up singing as career, sailed for a concert tour in the U.S.A.-where Bertha was to have followed him, had he succeeded - and met a mysterious shipboard accident. Instead of glowing reviews from the U.S.A., Bertha received his death notice.

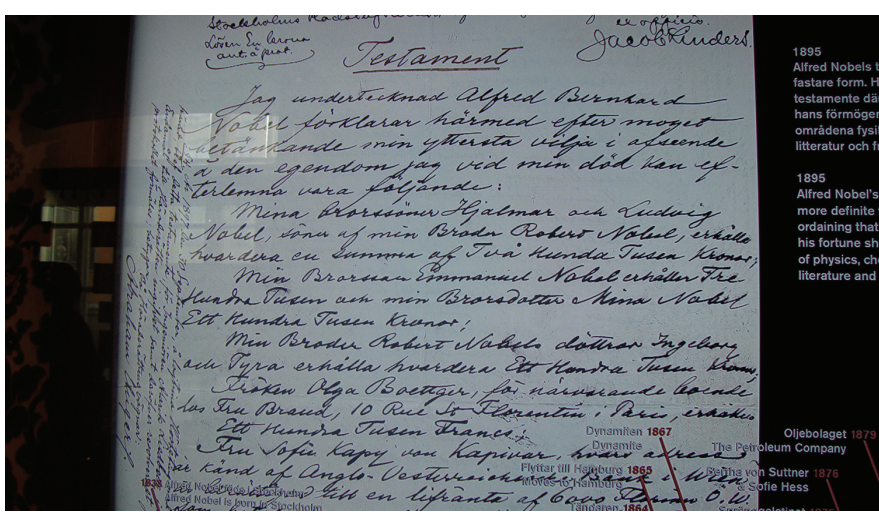

Nobel's will and testament

Since her father died a long time ago, and her mother gambled away the last piece of the family fortune, Bertha had to work to support herself. So she became a governess for three daughters of the rich von Suttner family. The son of the family, Arthur Gundaccar von Suttner, was studying in college and had difficulty with the courses in law. She helped him and he enjoyed the study, and they fell madly in love. But that was forbidden by the parents of Arthur Gundaccar since she was seven years older and came from a poor family. They often met in the garden in the night. One night the Suttner girls surprised to see the lovers in the garden, but they gave the pair their blessing and were delighted by their happiness. But such a love could not and did not last long. The mother became grew suspicious and began to spy, and she eventually caught the lovers in the garden one night. She wanted to dismiss the governess as soon as possible. Then came the advertisement from Nobel looking for a personal secretary and housekeeper and she answered it and accepted the offer. Bertha and Arthur changed "kisses salted with tears" and agreed that they would never see each other again. 
When Nobel met Bertha, he was surprised by her beauty, appearance and ability and the fact that she was not married. On the second day of her job, Nobel asked her "Is your heart free." She told him her story with Arthur. Nobel approved her behavior and advised her to cease correspondence with Arthur. "Eventually you will forget him, while he may forget you even sooner." Nobel was in love with her already and was making wishful thinking.

A few days later, when Nobel was away from Paris and Bertha remained at home, Bertha received two telegrams on the same day: one from Nobel telling her about his return in a week, and another from Arthur, that he could not live without her. She dropped everything and returned to the arms of Arthur. They married secretly without the blessing of Arthur's family (they did not get any money from the parents). On the other hand, it must have been a big blow to Nobel when he returned to the empty house, without any warning.

But Nobel and Bertha continued to correspond. A sense of strong emotion was still clearly visible in the letters of Nobel to her. When Bertha learnt that Sofie Hess was called Madame Nobel, she sent a telegram to Nobel to congratulate him. Nobel replied: "How can you seriously have believed I would have gone ahead and entered into matrimony-and done so without informing you? That would have been double high treason-against our Friendship and against Courtesy. The old bear is not yet so far gone as that... If I have not as yet responded to your so excellently amiable and friendly invitation, this is for a thousand reasons, which I would like to attempt in person... My hearty greetings to your husband! As far as you yourself are concerned, I do not need to tell you once more that I remain your affectionate and brotherly friend."

\section{A sketch of Nobel's life}

How to describe the life of Nobel? According to Wikipedia, “Alfred Bernhard Nobel (21 October 1833 - 10 December 1896) was a Swedish chemist, engineer, innovator, and armaments manufacturer. He was the inventor of dynamite."

Nobel also owned Bofors, which he had redirected from its previous role as primarily an iron and steel producer to a major manufacturer of cannon and other armaments. Nobel held 350 different patents, dynamite being the most famous. He used his fortune to posthumously institute the Nobel Prizes. The synthetic element nobelium was named after him. His name also survives in modern-day companies such as Dynamit Nobel and Akzo Nobel, which are descendants of the companies Nobel himself established."

It is interesting to compare this with a short autobiography of Alfred Nobel, written on the request from his brother Ludvig:
Alfred Nobel-pitiful creature, ought to have been suffocated by a humane physician when he made his howling entrance into this life. Greatest virtues: keeping his nails clean and never being a burden to anyone. Greatest weakness: having neither wife or kids nor sunny disposition nor hearty appetite. Greatest single request: to not be buried alive. Greatest sin: not worshiping Mammon. Important events in his life: none.

Since it is important to make explosives which are powerful and safe, Nobel spent a huge amount of time to improve compositions of explosives and techniques in manufacturing them, and thus obtained many more patents on explosives and explosive devices. It should be mentioned that he lost one brother and several of his workers to the dynamite he first invented dynamite.

Nobel was different from other inventors. He was also a very successful business man, marketing and managing his inventions and business. Because of this, he naturally became very rich. It is probably less known that another major source of his fortune came from his investment in

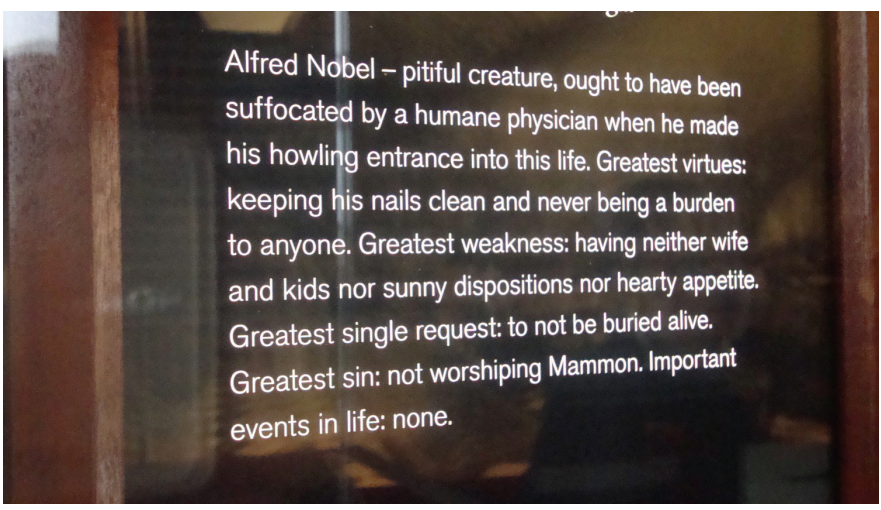

his family oil business in Russia. Overall, Nobel was a well-rounded scientist and business man.

The above brief summary does not do justice to the rich and complicated life of Nobel. We will give a brief description of the love life of Nobel in the next section. If the reader wants to know more about Nobel and the Nobel prizes, he or she can read some books on Nobel listed in the last section of this article.

\section{The love life of Nobel}

The love story between Nobel and Sofie Hess was mentioned before. Sofie Hess was one version of the Cinderella story, which has been made very popular by the Disney movie. Her mother died and her father married a widow with three daughters. She was very attractive and charming but her three stepsisters were ugly. Her stepmother knew it and wanted to exploit Sofie's beauty. Since the family was poor, Sofie did not get any education. Her step-mother trained her and wanted her to become a mistress of a rich person, whether young or old. They 
lived in Vienna and the Spa town Baden bei Wien was a few miles from Vienna and was frequented by rich people. Sofie became a flower girl in a flower shop where rich people often stopped. Everything was planned for the purpose of finding a rich gentleman.

After the disappointment with Bertha, Nobel made a stop to Baden during the business trip to Vienna and met Sofie.

When they first met in 1876 , Nobel was 43 years old, and Sofie about 20. They quickly became lovers. It is difficult to describe such a love relationship between a lonely super-rich old man and a young and charming girl whose family were looking for fortune.

It might be helpful to quote some letters from Nobel to Sofie. In a letter to Sofie in 1878, "I long to be off and back with you. As soon as possible, I will send you a wire or write to say where and when we can meet; until then I send you a thousand hearty greetings and wish you all good things."

In 1878, "Why are you worrying needlessly? Have you really not noticed how well I wish you, and that, least of all, am I any kind of seducer? While all I want is peace and quiet, you imagine me philandering all over the place. Can you not, once and for all, free yourself from this mare's nest of silly fantasies by using your common sense?"

In 1879, "Your little letter has just arrived and gave me much joy."

In 1880, "As I sit here so alone and forsaken, and so plagued by unpleasant tasks that it is completely destroying my already weakened nerves, then I feel in double measure how dear you are to me."

In 1880, "You speak of love: to me this feeling could not exist if it were't for all those eternal sorrows and torments... Take some good advice-do not waste your young life as you have done so far. Seek the bright sunshine and not the shadow, cheerful individuals and not a sad old log like me... Take advantage of my attitude toward you and find a safe harbor in your life... Don't chain your youth to a sorrowful old man..."

In 1884, "At my age, everyone feels a need to have someone for whom one lives, and whom one may hold dear. All you have to do was be this person, but for your part, you have done everything imaginable to make such a connection impossible."

In 1884, "You are always saying that I am incapable of loving anyone. This is completely wrong: I could even hold you dear if it were not your lack of education pains me and brings me humiliations. But what use are all my explanations? You can't even grasp that a man could attach such significance to concepts such as respect and self-esteem. If we had only been of the same mind on that point, things would not be as they are today..."

In 1888, "This evening I am going to the theater for the first time, but alone, and because I am always alone now, nothing amuses me."

Towards the end of 1890, Nobel learned that Sofia was pregnant by another man and he wanted to break off their relationship. In 1891, Sofie wrote: "My dear Alfred, if I may still call you that, because in spite of the terrible shame I have to suffer you are not yet erased from my heart. You should know that there is no foundation for all the accusations against me. They have been conspiring and plotting against me here, but everything of which I am accused you take as truth makes me more than unhappy..."

In 1891, Nobel wrote: "Dear Sofie, As is evident from your letters, poor little one, you have suffered much and have had to atone too harshly for many of your earlier mistakes... There is only one thing I will never forgive-when someone tries to make me look ridiculous. I have warned you about this for many years, but as the saying goes: against stupidity even the gods fight in vain!"

\section{One explanation for the most popular reason of why there is no Nobel prize in mathematics}

How to explain the most popular reason for no Nobel prize in mathematics? One natural guess might be that the man who made Sofie pregnant was a mathematician. Actually, he was not. He was a young Austrian cavalry officer, called Kapy von Kapivar.

Since it is probably known that mathematicians are usually not so good at finding girlfriends ${ }^{3}$, when some mathematicians asked or complained why there is no Nobel prize in math, other people snapped back: "You mathematicians are so good and stole the girlfriend of Nobel!"

It could also be the case that some proud mathematicians tried to explain why there is no Nobel prize in math: "Some mathematicians took away the girlfriend from Nobel!"

What is the reason for no Nobel prize in mathematics? As Garding and Hörmander explained, the reason for no Nobel prize in mathematics is that "for natural reasons, the thought of a prize in mathematics never entered Nobel's mind."

The reason given by Garding and Hörmander seems to be very reasonable. Nobel did not use much mathematics in his work or business, and did not enjoy mathematics either. As explained above, he had direct motivations to set up a prize in each of the five categories and was a very practical man. Therefore, the answer for the question of no Nobel prize in mathematics is very clear: there was no reason why he might consider it or do it. It should be pointed out that he was aware of mathematics and interacting with some distinguished mathematicians such at Mittag-Leffler. His interests in the female mathematician Kowalevski supports this.

Of course, mathematics has changed since the Nobel time. If Nobel had written his will 100 years later, in 1995, he might have included mathematics. One reason is that a

\footnotetext{
${ }^{3}$ There are always exceptions to any general statement.
} 
busy business man like him could not avoid the use of digital and information technologies resulting from mathematics. As mentioned before, one of his major incomes came from the oil business. Mathematics has also played an important role in the deep sea oil exploration. Since the Nobel Prize in economics, or more precisely the Nobel Memorial Prize in Economic Sciences, was established in 1968 by Sweden's central bank Sveriges Riksbank, there might be a possibility that a rich organization or person who likes mathematics could establish a Nobel prize in mathematics in the future.

\section{Some books on Nobel}

Though the Nobel prize is so famous, there are not too many biographies about Nobel. I have borrowed all books about him from the Library system of University of Michigan and the Ann Arbor District Library.

They are all interesting and shed different aspects of the life of Nobel. I add some comments after each title.

Here is the list:

1. Alfred Nobel and the Story of the Nobel Prize, by John Bankston, Mitchell Lane Publishers, 2004. 48 pages.

This is the first biography about Nobel I read. It is a biography for children, and I wanted to borrow some biographies of great people for my youngest daughter. It is a fascinating book. The first Chapter Merchant of Death is unique and attracts one's attention right away. After reading this, I wanted to borrow all books about Nobel.

2. Alfred Nobel: A Biography, by Kenne Fant; translated from the Swedish by Marianne Ruuth, Arcade Publishing, 1993. viii+342 pages.

This is a comprehensive and serious biography of Nobel. A unique and important feature is that it contains excerpts of many letters of Nobel to his girlfriend. On page 119 , it says:

The following sections contain excerpts of some 218 preserved and numbered letters Alfred wrote to Sofie Hess from 1878 to 1895 . From a strictly biographical point of view, they are priceless, but they raise a specter that faces biographers: does anyone have the right to publish correspondence that was obviously never meant to be made public? The dilemma is complicated by the fact that Alfred expressly requested Sofie to destroy his letters immediately after reading them-a request she did not heed. Meanwhile, Sofie kept copies of all her letters to Alfred, but the only ones that still exist today date from early 1891, soon after Alfred had learned of her pregnancy. Not long after Alfred's death, the Nobel Foundation came to an agreement with Sofie, exchanging a sum of money for the letters. Sofie did not hand all of them over, however, hoping to extract more money from the foundation later-a ploy that was not successful. For its part, the foundation kept the letters a secret until 1950, when it permitted scholars and historians to view them. The day was long past when they might have harmed Nobel's name or the mission of his final will, and the view they give of his life and times is invaluable.

3. Alfred Nobel: Inventive Thinker, by Tristan Boyer Binns, Danbury, Conn., Franklin Watts, 2004. 111 pages.

This is a standard good biography for young people. It contains standard facts about the work and life of Novel. It is concise. For example, it gives a good summary of the complicated relationship between Nobel and Hess:

When Nobel and Hess were in the same place, they met often, but they were usually apart. They wrote hundreds of letters to each other. Sometimes, they wrote every day. Hess wrote about money and everyday dramas. Nobel wrote about his business concerns, his health, and his opinions about other people. He valued Hess's openness about her emotions... He was first drawn to her uncomplicated, straightforward way of seeing the world. She clearly thought he was nice enough and liked how rich he was. Hess had little education. Nobel valued an educated mind and thoughtful conversation more than almost anything else. He tried to teach her more things and showed her more of how the world worked. Perhaps a different teacher could have changed Hess's manner and helped her learn a new way of thinking, but Nobel only grew more upset with her. She hated the way he wrote to her, as if he was better than her.

Nobel never proposed marriage to her, but he started calling her Madame Nobel... When Bertha von Suttner heard about Madame Nobel and wrote Nobel a card to congratulate him on his marriage, Nobel said he had neither a wife, nor a mistress.

Bertha von Suttner was the woman Nobel really liked or loved, and this emotion was strong and kept on till the end of his life.

4. Alfred Nobel, dynamite king, architect of peace, by Herta E. Pauli. New York, L.B. Fischer, 1942, 336pp. (Reprinted by Kessinger Publishing, LLC in 2008).

This book was written before the letters between Nobel and his girlfriend were open to the public in 1950 . There was no mention of Sofie Hess in this book at all. This might also explain that their relationship was not so well-known. The reason is that the Nobel prize was well-established by1940 and everyone in the world has been interested in who get the Nobel prize but do not really care (or care to ask) too much about the person Alfred Nobel.

5. Alfred Nobel: Networks Of Innovation, by Ulf Larsson. Nobel Museum; Sagamore Beach, MA: In association 
with Science History Publications/USA, 2008, 216 pages.

This book was published in conjunction with an exhibition in the Nobel museum. It contains many valuable pictures and also some interesting facts. For example, on page 167 , it says:

She [Sofie] has the soul of a three-year old in a more than 36-year old body. Alfred Nobel wrote this statement in a draft of a letter to Julis Heydner... Sofie was in fact not 36, but 43 years old. Alfred and Sofie's relationship has been full of secrets and lies from the very beginning. When they met, Sofie told Alfred that she was only 18, when in fact, she was 25. Did she want to appear more attractive and innocent, like a young girl who needed to be taken care of? Alfred never learned Sofie's true age.

6. Alfred Nobel, the Loneliest Millionaire, by Michael Evlanoff and Marjorie Fluor. Foreword by Simon Ramo. Commentaries by Arnold O. Beckman and Henry T. Mudd. W. Ritchie Press, 1969, 336 pages.

This is the most readable and romantic biography of Nobel. In order to express the romantic life and render the feeling of the Nobel women better, the main author Michael Evlanoff asked the female joint author, Marjorie Fluor, to work on the parts on the love life of Nobel. It makes one wonder how much information provided in this book is true and based on facts. For example, this book described an early tragic love story of Nobel during his youth. The author of the next book vouched for this story after talking to some staff member of the Nobel foundation (this story was known in the Nobel family). This book gives a vivid and detailed description of the first acquittance of Nobel with his only long term girl friend Sofie Hess. For example:

Alfred bade Sofie goodnight at the door of the tumbledown old house where she had taken a room in order to be near her job... He told her that he must catch a train back to Paris the next day to attend urgent business. When her lips dropped and she turned a disappointed face away from him, he lifted her chin with gentle fingers to watch happiness again light up her glorious eyes.

\section{or}

The girl's delight over the jeweled bracelet was too great for her to consider returning to her sale girl position that afternoon... When she at last reached home, she opened the creaking door and aroused the household with cries of greeting that brought her mother and sisters to her in alarm. But her radiant face told them she was not ill, not even upset. She threw herself into her mother's arms holding up the bracelet for all of them to see.
7. Champions of peace: The Story of Alfred Nobel, the Peace Prize and the Laureates, by Tony Gray, Paddington Press, 1976. 320 pages.

The major portion of this book is concerned with the Nobel prize in peace. It gives a very good description of the beginning of how Nobel's will was carried by his last young assistant Ragnar Sohlman by settling very complicated situations by clever and daring methods. On page 55 , it says:

While the courts were considering the test cases which had been brought, all the Nobel securities in Paris were being transferred, partly to London and partly to Stockholm, in postal packages insured by the banking firm of Rothschild, since the French post office could not insure any packages worth more than 20,000 francs. The Rothschild firm stipulated that shipments on any single day should not exceed 2.5 million francs, so for a week or more, securities worth that amount were drawn every day from the vaults in Paris and posted to London or Stockholm. The actual method of transfer was a real James Bond operation, with Sohlman seated in a horse cab with a loaded revolver in his hand, fully prepared to defend the suitcase he was taking to the Swedish Consulate for packaging and dispatch to the Gare du Nord "in case a collision with another carriage had been arranged by robbers."

8. Alfred Nobel, the Man and his Work. With a supplement on the Nobel institutions and the Nobel prizes, by Nils K. Stahle, translated by Alan Blair. Nelson, 1962, 222 pages.

This is a more serious biography of Nobel and contains a preface written by the famous English Prime Minister Winston Churchill. The last section is titled $A$ brief Survey of Alfred Nobel's Personality and the last subsection is The Women in Alfred's Nobel's Life. It ends with: "One cannot help wondering what would have happened had Alfred Nobel in his mature years been happily united to the right type of woman who would have helped and understood him..."

Probably one answer to the above question might be that there would be no Nobel prize if Nobel had a wife and children. The world should thank the immature, unfaithful and wasteful girlfriend, Sofie Hess, of Nobel. (I visited Stockholm and the Nobel museum during my trip to Institut Mittag-Leffler. When I first arrived at the institute, the secretary showed me around the impressive building which was the former house (or mansion) of Mittag-Leffler. Since I did not know anything about Mittag-Leffler's family, I asked her what happened to his children, a very naive question. She said that he had no children and that's why we have the mathematics institute here!

The reader may now have a very bad opinion of Sofie Hess. To be fair, it is perhaps helpful to quote from the 
biography “Alfred Nobel” by Kenne Kant. On page 118, he writes:

The ten-year period between 1883 and 1893 was Nobel's most strenuous. It was clear from his letters that Alfred was near exhaustion from all the legal battles and accidents. Sofie's extravagances were becoming increasingly a source of irritation... Alfred wrote of injustices, real and imaginary, and Sofie quite reasonably tired of the subject. No longer does she bother to reassure him that he is the only one for her. She was tired of being courted by correspondence. He had denied her virtually any chance of having her own social life, since her mode de vie (life style)-despite Alfred's supposedly enlightened views about education for women and his hopes that Sofie would refine herself-was essentially that of a kept woman. With a few notable exceptions, she was only permitted to see servants and her own sisters. It is hardly surprising that she grew restless and resentful.

9. The Nobel Prize: The First 100 Years, edited by Agneta Wallin Levinovitz, Nils Ringertz, World Scientific Pub. Co. Inc., 2001, 248 pages.

This book is mainly about the Nobel prize. It contains one article about Nobel the person, entitled "The Life and Philosophy of Alfred Nobel," written by the director of the Center of History of Science at the Royal Swedish Academy of Sciences. This article might explain why the love life of Nobel was not so well-known to the public now. It says: "Alfred Nobel was lonely and he was clearly unlucky in love, but such accounts are not so instructive. Romantic tales constitute a special genre, to which I shall not attempt to contribute."

From the discussion above, it is not clear whether the sad love life of Nobel was a matter of being unlucky for Nobel.

10. Nobel, the Man and his Prizes, edited by the Nobel Foundation and W. Odelberg, American Elsevier Pub. Co., 1972, 659 pages.

This is the third edition of a book published in 1950 by the Nobel Foundation to summarize its activities in the past 50 years. The main part is devoted to the Nobel prizes. It also contains a short biographic sketch of Alfred Nobel and a lengthy article by Ragnar Sohlmn, the last assistant of Nobel and the main executer of the will of Nobel, about the life of Nobel and the formation of the Nobel Foundation. There is no description of the love life of Nobel in this book at all, and the name of Sofie Hess was not mentioned.

The first paragraph of this book is still relevant:

Probably few Swedish names are better known throughout the world than that of Alfred Nobel, and yet the general public knows very little about him. It recalls that he was a great inventor, but not exactly of what, besides dynamite, remains vague; it also knows that he was a great prize donor. But of his personal character hardly anyone has much of a notion, and if certain people have visualized him in their minds, the picture is not, as a rule, flattering. At times, some have imagined him to have been an uneducated man, somewhat vain and fond of both publicity and personal attention. But this picture is just the opposite of the true one.

In the spirit of this book, the official website of the Nobel foundation ${ }^{4}$ contains some information about Nobel: But it does not mention Sofie Hess at all. This seems to be in strong contrast with the exhibition in Nobel Museum. Maybe one reason is that they do not want to publicize too much the private life of Nobel, but still want to provide a true picture of his life to the visitors to the museum, who are mostly from the local area and neighboring countries.

\footnotetext{
${ }^{4}$ http://www.nobelprize.org/alfred_nobel/biographical/
} 